\title{
The Influence of China Demographic Structure on Social Security Expenditure-Based on Panel Data Model
}

\author{
Shichang Shen, Ying Wu \\ School of Mathematics and Statistics, Qinghai Nationalities University, Xining, China \\ Email: 13909785766@163.com
}

How to cite this paper: Shen, S.C. and $\mathrm{Wu}, \mathrm{Y}$. (2018) The Influence of China Demographic Structure on Social Security Expenditure-Based on Panel Data Model. Open Journal of Statistics, 8, 556-561. https://doi.org/10.4236/ojs.2018.83036

Received: May 23, 2018

Accepted: June 12, 2018

Published: June 15, 2018

Copyright $\odot 2018$ by authors and Scientific Research Publishing Inc. This work is licensed under the Creative Commons Attribution International License (CC BY 4.0).

http://creativecommons.org/licenses/by/4.0/ (c) (7)

Open Access

\begin{abstract}
Based on the panel data of 31 provinces and municipalities in China from 1998 to 2016, this paper studies the effect of demographic structure on social security expenditure in China by using entity fixed effect regression model. The results show that there is a long-term co-integration relationship between population aging and social security expenditure in the demographic structure, and there is a positive correlation between population aging and social security expenditure. And the different cross-sectional effects in 31 regions of China reflect the difference between population aging and social security expenditure in different regions of China.
\end{abstract}

\section{Keywords}

Population Aging, Social Security Expenditure, Entity Fixed Effect Regression Model

\section{Introduction}

The population aging is an inevitable result of the transformation of demographic structure. In the first half of the 21st century, China will become the developing country with the highest degree of aging. During the 30 years of strict implementation of Family Planning, new problems have emerged in Chinese population environment, such as the long-term decline in fertility, the aging acceleration and labor shortage in the future. Looking forward to the development of China in the 21st century, population aging will further affect Chinese demographic structure and social development. Therefore, many scholars have discussed the relationship between population aging and social security expenditure. Zhang Tianfang [1] (2006) established a non-parametric regression model 
to analyze the dynamic relationship between population aging and the expenditure of social security and employment. The research shows that the population aging is increasing in China, and government finance will face more pressure on the expenditure of social security and employment. Tong Yufen and Liu Guangjun [2] (2008) took Beijing as an example to establish a binary linear regression equation, which found that the proportion of the expenditure of social security and employment will increase by about 2.029 percentage points if the proportion of aging of population over 65 increases by 1 percentage point. Li Hongxin and Li Wei [3] (2012) used time series data and took the dependency ratio of the elderly population as control variable to establish regression model, which noted that aging of population increases fiscal expenditure by contributing to an increasing in fiscal expenditure on social security and employment. Liu Luji [4] (2014) analyzed the relationship between population structure and the financial expenditure of social security with using the elderly population dependency ratio and children dependency ratio as the core explanatory variables. Zhang Pengfei and Su Chang [5] (2017) used SYS-GMM to study the effect of aging of population and social security expenditure on financial burden. However, this paper uses panel data from 1998 to 2016 to analyze the direct influence of population aging on social security expenditure by establishing entity fixed effect regression model.

\section{Theoretical Basis}

The general form of the entity fixed effect regression model [6] for panel data is that:

$$
y_{i t}=\delta+\lambda_{i}+\sum_{k=2}^{K} \beta_{k} x_{k i t}+\mu_{i t}
$$

Null hypothesis for the test of the model is that: $H_{0}$ :

$\lambda_{1}=\lambda_{2}=\lambda_{3}=\cdots=\lambda_{N-1}=0$. Under the null hypothesis $H_{0}$, we obtain the following:

$$
F=\frac{(R R S S-U R S S) /(N-1)}{U R S S /(N T-N-K+1)} \sim F(N-1, N(T-1)-K+1)
$$

Among them, RRSS is the sum of the residuals of the mixed regression model, and URSS is the sum of the square of the entity fixed effect regression model. $N$ is the number of sections and $T$ is the number of time points, and $K$ is the number of explanatory variables. Therefore, it is reasonable to set the model as an entity fixed effect model if null hypothesis is rejected at a given significance level.

\section{Empirical Analysis}

\subsection{Data Selection and Description}

This paper chooses elderly dependency ratio and social security expenditure as independent variable and dependent variable. The social security expenditure is divided into absolute index and relative index. Absolute index refers to the ex- 
penditure of per capita financial social security which excludes the influence of the total population. Relative index refers to the proportion of fiscal social security expenditure in Gross Domestic Product. Absolute index is used in this paper. Because Chinese fiscal expenditure statistical caliber was adjusted in 2007, and China liberalized its Two-child policy after 2016, which would certainly have an impact on the expenditure of social security. Therefore, this paper selects the data from 1998 to 2016 for study. The data are derived from China Statistical Yearbook and China Demographic Yearbook. In order to avoid the heteroscedasticity in the process of analysis, the data are on a logarithm analysis and denoted as $\ln S$ and $\ln O$, respectively.

\subsection{Unit Root Test}

If two mutual independent variables have unit roots, they will appear pseudo-regression. Therefore, in order to avoid the pseudo-regression between Social Security Expenditure and Elderly Dependency Ratio, we must test the stationarity of the two variables, firstly.

From the time sequence diagrams of the two variables, we can see that all the two variables have an obvious upward trend, so the unit root test including individual intercept and trend is used.

Table 1 shows that the two horizontal sequences of $\ln S$ (which refers to social security expenditure and is an explained variable) and $\ln O$ (which refers to elderly dependency ratio and is an explanatory variable) have at least 4 $\mathrm{P}$-values less than $5 \%$ at $5 \%$ significant level, indicating that the null hypothesis that there are unit roots in the two horizontal sequences is rejected, so the two horizontal sequences are stable.

\subsection{Co-Integration Test}

According to the co-integration theory, if there was a long-term co-integration relationship between $\ln S$ and $\ln O$, they would have the same order. Because the horizontal sequences of $\ln S$ and $\ln O$ are stationary, which meet the premise of co-integration.

It is not difficult to see from Table 2 that the Panel rho-Statistic and Group rho-Statistic of Pedroni-test cannot reject the null hypothesis without co-integration relationship, but the other statistics of Pedroni-test reject the null hypothesis, and the ADF statistics of Kao-test rejects the null hypothesis that there is without co-integration, so we can think that $\ln S$ and $\ln O$ have co-integration relationship (Figure 1 and Figure 2).

Table 1. Unit root test.

\begin{tabular}{cccccc}
\hline variables & LLC & Breitung & IPS & Fisher-ADF & Fisher-PP \\
\hline \multirow{2}{*}{ LnS } & -9.83496 & 2.73659 & -5.68917 & 149.753 & 169.315 \\
& $(0.0000)$ & $(0.9969)$ & $(0.0000)$ & $(0.0000)$ & $(0.0000)$ \\
\multirow{2}{*}{ LnO } & -5.77779 & -5.85274 & -3.70324 & 101.302 & 91.4300 \\
& $(0.0000)$ & $(0.0000)$ & $(0.0001)$ & $(0.0012)$ & $(0.0089)$ \\
\hline
\end{tabular}


Table 2. Co-integration test (test results and test results).

\begin{tabular}{ccccc}
\hline \multicolumn{4}{c}{ Alternative hypothesis: common AR coefs. (within-dimension) } \\
\hline & Statistic & Prob. & Weighted Statistic & Prob. \\
Panel v-Statistic & 41.49205 & 0.0000 & 42.04641 & 0.0000 \\
Panel rho-Statistic & 0.078105 & 0.5311 & -0.153613 & 0.4390 \\
Panel PP-Statistic & -12.57958 & 0.0000 & -12.37828 & 0.0000 \\
Panel ADF-Statistic & -3.212892 & 0.0007 & -3.281447 & 0.0005 \\
Alternative hypothesis: individual AR coefs. (between-dimension) & \\
\multicolumn{5}{c}{ Statistic } \\
Group rho-Statistic & 2.336004 & Prob. & \\
Group PP-Statistic & -3.545959 & 0.9903 & \\
Group ADF-Statistic & -3.006709 & 0.0002 & \\
ADF (Kao test) & -4.596027 & 0.0013 & \\
\hline
\end{tabular}

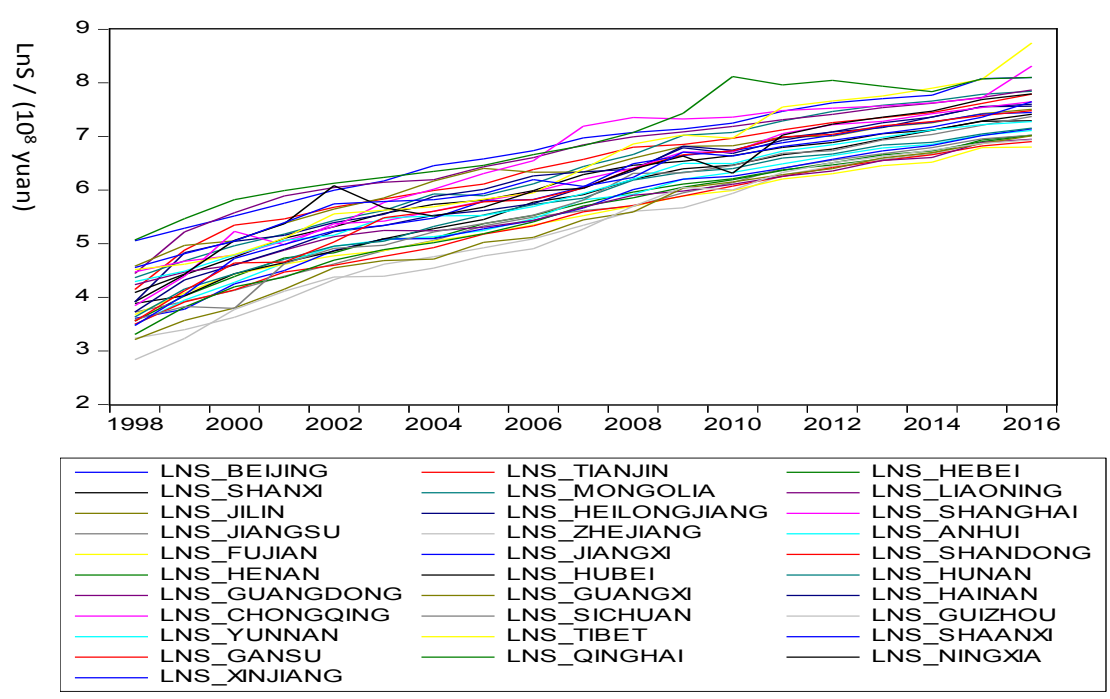

Figure 1. Time series diagrams of $\ln S$.

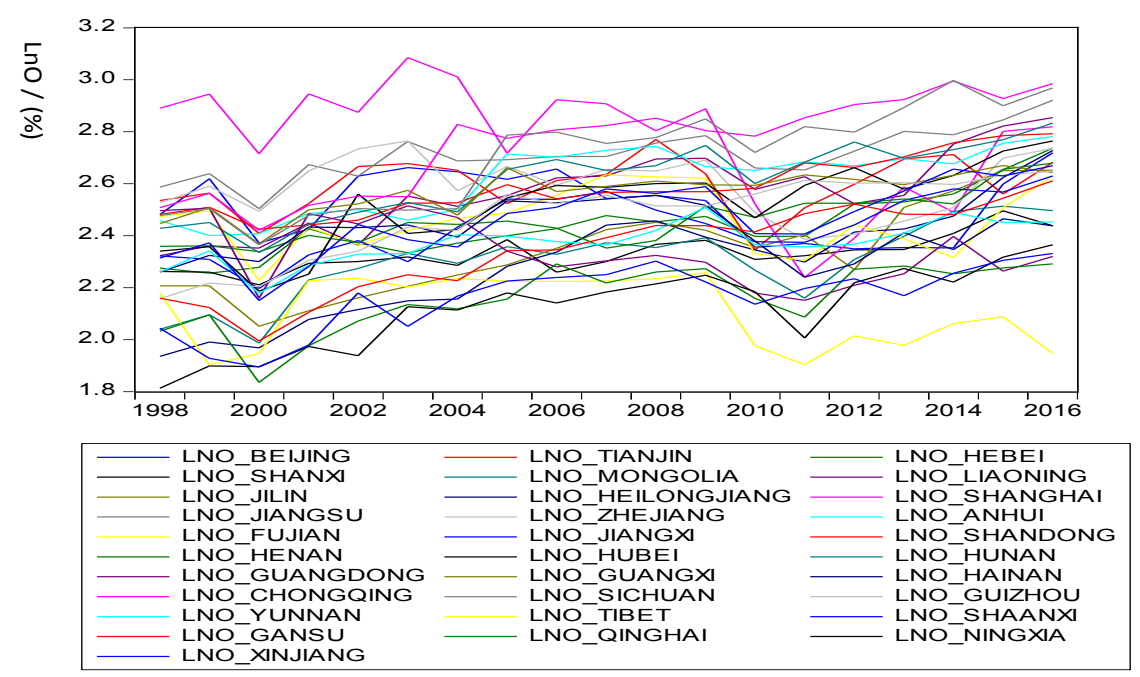

Figure 2. Time series diagrams of $\ln O$. 


\subsection{Model Estimation}

\subsubsection{Likelihood Ratio Test (LR Test)}

The null hypothesis of LR-test is that the fixed effect is superfluous, so it is clear from the results of Table 3 that the original hypothesis is rejected at 5\% confidence interval, that is, introducing the fixed effect is appropriate.

\subsubsection{Model Form}

By calculation, we obtain that:

$$
F=\frac{(720.1091-436.8212) / 558}{436.8212 / 30}=30.66246
$$

Among, $U R S S=720.1091, U R S S=436.8212 ; N=31, T=19, K=1$. At a given significance level of $5 \%$, the corresponding critical value from the F-distribution table are that: $F_{\alpha}(30,558) \approx 1.46$. Because of $F>1.46, H_{0}$ being refused, the introduction of entity fixed effect regression model is appropriate. Therefore, we obtain the regression coefficients for the model.

$$
\ln S=-4.598746+4.302043 \ln O+\lambda_{i},
$$

( $i=1 \_$Beijing, 2_Tianjin, ..., 31_Xinjiang).

From the above model, we can see that population aging has a positive correlation with social security expenditure. And it is clear that every $1 \%$ increase in population aging, social security expenditure will increase by $4.302043 \%$. The cross-sectional effects in Table 4 (the cross-sectional effect data of 31 regions in China show the degree of deviation from the overall mean) reflect the difference between population aging and social security expenditure in different regions of China.

\section{Conclusions}

This paper uses static panel model to study the relationship of population aging and social security expenditure in China from 1998 to 2016. The empirical results show that: 1) the population aging has a significant positive impact on social security expenditure, and there is a long-term co-integration relationship between them. 2) Per capita expenditure on social security expenditure will increase by 4.302043 percent for an increase of 1 percent in population aging. 3) a) From the regression results of Table 4, we can see that the cross-section effects of Qinghai, Tibet, Ningxia and Xinjiang are obvious, which lead to the increase of intercept terms of linear equation, reflecting that population aging in the west regions of China has great impact on social security and employment spending because of the low level of economic development and living standards in the

Table 3. Fixed effect test (LR test).

\begin{tabular}{cccc}
\hline Effects Test & Statistic & d.f. & Prob. \\
\hline Cross-section F & 12.040844 & $(30,557)$ & 0.0000 \\
Period F & 294.427880 & 30 & 0.0000 \\
\hline
\end{tabular}


Table 4. Regression results of the model.

\begin{tabular}{cccccc}
\hline Regions & $\begin{array}{c}\text { Effects of } \\
\text { cross-section }\end{array}$ & Regions & $\begin{array}{c}\text { Effects of } \\
\text { cross-section }\end{array}$ & Regions & $\begin{array}{c}\text { Effects of } \\
\text { cross-section }\end{array}$ \\
\hline 1_Beijing & 0.542103 & 12_Anhui & -0.997632 & 23_Sichuan & -1.315523 \\
2_Tianjin & -0.164709 & 13_Fujian & -0.494906 & 24_Guizhou & -0.780011 \\
3_Hebei & -0.276577 & 14_Jiangxi & -0.282374 & 25_Yunnan & 0.353008 \\
4_Shanxi & 0.621482 & 15_Shandong & -1.077571 & 26_Tibet & 1.980996 \\
5_Mongolia & 1.074443 & 16_Henan & -0.472158 & 27_Shaanxi & -0.007736 \\
6_Liaoning & 0.183299 & 17_Hubei & -0.419379 & 28_Gansu & 0.505121 \\
7_Jilin & 0.847504 & 18_Hunan & -0.882014 & 29_Qinghai & 2.223997 \\
8_Heilongjiang & 0.933642 & 19_Guangdong & 0.222020 & 30_Ningxia & 1.672924 \\
9_Shanghai & -0.753308 & 20_Guangxi & -1.088594 & 31_Xinjiang & 1.497526 \\
10_Jiangsu & -1.520621 & 21_Hainan & 0.260937 & & \\
11_Zhejiang & -1.273520 & 22_Chongqing & -1.112372 & & \\
\hline
\end{tabular}

western regions; b) The cross-section effects of Jiangsu, Sichuan, Zhejiang and Chongqing are negative, and its absolute values are larger, and as a result, the intercept terms of the linear equation are reduced, reflecting that population aging in the central regions of China has less impact on social security and employment spending because of the better economic development and the higher living standards of the people than the western in these regions.

\section{Funds}

This work is supported by the National Natural Science Foundation of China (No. 11561056) and Natural Science Foundation of Qinghai (No. 2016-ZJ-914).

\section{References}

[1] Zhang, T.F., Wang, L. and Lu, W.Y. (2006) The Dynamic Relationship between Population Aging and Social Security Expenditure. Statistics and Decision, No. 22, 78-79.

[2] Tong, Y.F. and Liu, G.J. (2008) Population Aging and Its Influence on Social Security Expenditure in Beijing. Population and Development, No. 4, 14-20.

[3] Li, H.X. and Li, W. (2012) The Influence of Population Aging on the Scale of Financial Expenditure in China-From the Perspective of Social Security. Population and Society, No. 4, 33-37.

[4] Liu, L.J., Li, Q. and Zhang, X.D. (2014) Evolution of the Demographic Age Structure and Fiscal Social Security Expenditure level-Based on the Empirical Analysis of Provincial Panel Data. Journal of Guizhou University of Finance and Economics, No. 4, 91-97.

[5] Zhang, P.F. and Su, C. (2017) Population Aging, Social Security Payment and Fiscal Burden. Public Finance Research, No. 12, 33-44.

[6] Bai, Z.L. (2008) Econometric Analysis of Panel Data. Nankai University Press, Tianjin. 